\title{
Um Enfoque sobre o Conteúdo Informacional dos Parágrafos de Ênfases e de outros Assuntos no Relatório dos Auditores Independentes de Companhias Abertas ${ }^{1}$
}

\author{
Un Enfoque Acerca del Contenido Informativo de los \\ Párrafos de Énfasis y de Otras Cuestiones en el Informe de Los \\ Auditores Independientes de Compañias Abiertas
}

\section{A Focus Over the Informational Purport From the Emphasis Paragraph and Other Topics from The Open Companies Independent Auditor's Report}

\author{
Edilane Cristina da Silva \\ Graduado em Ciências Contábeis UFPB \\ Endereço: Universidade Federal da Paraíba, Centro de Ciências Sociais Aplicadas - Campus I. \\ Campus Universitário I, Cidade Universitária, CEP: 58051-900 - Joao Pessoa, PB - Brasil \\ Telefone: (83) 3216-7459, e-mail: edilanne@hotmail.com
}

Manoel Victor Benevides Aires

Endereço: Universidade Federal da Paraíba, Centro de Ciências Sociais Aplicadas - Campus I. Campus Universitário I, Cidade Universitária, CEP: 58051-900 - Joao Pessoa, PB - Brasil Telefone: (83) 3216-7459, e-mail: manoel.mvba@hotmail.com

Karla Katiuscia Nobrega de Almeida Professora Assistente da Universidade Federal da Paraíba Endereço: Universidade Federal da Paraíba, Centro de Ciências Sociais Aplicadas - Campus I. Campus Universitário I, Cidade Universitária, CEP: 58051-900 - Joao Pessoa, PB - Brasil Telefone: (83) 3216-7459, e-mail: kknalmeida@gmail.com

\section{RESUMO}

O relatório do auditor independente possui conteúdo informacional disciplinado pelas Normas Brasileiras de Contabilidade - Técnicas de Auditoria Independente - NBC Ta's, série 700, de observância obrigatória a partir de 2010. Seu conteúdo está disposto em várias seções, dentre as quais se encontram os parágrafos de ênfases e os parágrafos de outros assuntos, disciplinados, especialmente, pela NBC TA 706. Nesta perspectiva, esta pesquisa objetiva identificar os fatos abordados nos parágrafos de ênfase e nos parágrafos de outros assuntos dos relatórios de auditoria emitidos para as companhias abertas pertencentes aos níveis diferenciados de governança corporativa da BM\&FBOVESPA e analisar o tratamento destes, quanto às orientações estabelecidas nas NBC TA's que regulam o assunto. Para tanto, realizou-se pesquisa descritiva, bibliográfica e documental, sobressaindo-se o aspecto de estudo qualitativo. Coletou-se os relatórios dos auditores independentes para os exercícios sociais de 2010 e 2011 de 31 sociedades. Os resultados encontrados permitiram identificar o assunto "critérios contábeis

\footnotetext{
${ }^{1}$ Artigo recebido em 24.09.2013. Revisado pelos pares em 17.09.2014 (blind review). Ajustado e Aceito para publicação em 11.09.2014. Recomendado para publicação por José Ribamar Marques de Carvalho (Editor Científico). Publicado em 30.12.2014. Organização responsável UACC/CCJS/UFCG.
} 
divergentes" inserido em todos os relatórios analisados que fizeram uso do parágrafo de ênfase, tanto em 2010, com em 2011. No parágrafo de outros assuntos, identificou-se a menção sobre "informação suplementar" e "auditoria dos valores correspondentes do exercício anterior" nos dois anos. Concluiu-se que o assunto "reapresentação das demonstrações contábeis" é tratado pelas NBC TA's e nos relatórios dos auditores independentes analisados, de forma ambígua, quando se relaciona a seção/parágrafo destinado a sua menção.

Palavras-chave: Auditoria Independente. Relatório. Ênfase.

\begin{abstract}
The independent auditor's report has its informational purport disciplined by the Brazilian Accounting Standards Independent Audit Technique - NBC (BAS) Ta's, series 700, which compliance is required since 2010. Its purport is arranged in several sections, among which we can find the emphasis paragraph and other contents paragraphs, specifically disciplined by the NBC TA 706. Under this perspective, the actual research aims to identify the facts approached at the emphasis paragraphs and at the other contents paragraphs from the audit's report, forwarded to the open companies belonging to highlighted levels of corporate governance from BMEBOVESPA as well as analyze its usage regarding the guidelines established by the NBC TA's that regulates the this subjects. For this, we accomplished a descriptive, bibliographic and documental research, focusing on the qualitative study aspect. The independent auditor's reports had been gathered to the social assignment from 2010 and 2011 of 31 societies. The results found allowed us to identify the subject "divergent accounting criteria" inserted in all analyzed reports that had used the emphasis paragraphs both in 2010 and 2011. On other contents paragraphs we identified mentions about "supplementary information" and "audit of the values corresponding to the previous assignment" in both years. We concluded that the theme "restatements of the accounting demonstrations" is stated by the NBC TA's and also in the independent auditor's report analyzed, in ambiguous way when it regards the section/paragraph for its reference.
\end{abstract}

Keywords: Independent audit. Report. Emphasis.

\title{
RESUMEN
}

El dictamen del auditor independiente tiene contenido informativo disciplinado por las Normas Brasileñas de Contabilidad Técnicas de Auditoría Independiente - NBC Ta's, serie 700, de ejecución obligatoria desde 2010. Su contenido está dispuesto en varias secciones, en las que se hallan los párrafos de énfasis y los párrafos de otras cuestiones, disciplinados, especialmente, por la NBC TA 706. Por lo tanto, esta investigación objetiva identificar los hechos abordados en los párrafos de énfasis y en los párrafos de otras cuestiones de los informes de la auditoría, emitidos a las compañías abiertas pertenecientes a los niveles diferenciados de gobierno corporativo de la BMEFBOVESPA y analizar su tratamiento, respeto a las orientaciones establecidas en las NBC TA's que reglan el contenido. Por lo tanto, realizamos investigación descriptiva, bibliográfica y documental, sobresaliéndose el aspecto de estudio cualitativo. Recogemos los informes de los auditores independientes para los ejercicios sociales de 2010 y 2011 de 31 sociedades. Los resultados encontrados permitieron identificar el contenido "normas contables divergentes" insertadas en todos los informes analizados que utilizaron el párrafo de énfasis, tanto en 2010, como en 2011. En el párrafo de otros contenidos, identificamos la referencia sobre "información suplementaria" y "auditoría de los valores correspondientes del ejercicio anterior" en los dos años. Concluimos que El contenido "representación de las demonstraciones contables" es tratado por las NBC TA's y en los informes de los auditores independientes analizados, de forma confusa, cuando se relaciona a la sección/párrafo destinado a su referencia.

Descriptores: Auditoría Independiente. Informe. Énfasis.

\section{INTRODUÇÃO}

O cenário contábil brasileiro dos últimos anos tem experimentado mudanças normativas que alcançam inclusive a atividade de auditoria independente e, no esforço de adequação aos padrões internacionais, observa-se a adesão brasileira as International Standard on Auditing - ISA's, através das Normas Brasileiras de Contabilidade - Técnica de Auditoria Independente (NBC TA's), dentre outras. 
De observância obrigatória a partir de $1^{\mathrm{o}}$ de janeiro de 2010, as NBC TA's abordam diversos aspectos técnicos relacionados com a atividade de auditoria independente das demonstrações contábeis, tais como as modificações no formato do relatório do Auditor Independente, assunto abordado na presente pesquisa.

Regulamentado pelo conjunto das NBC Ta's 700, o relatório do auditor independente possui conteúdo informacional disposto em várias seções, dentre as quais se encontra os parágrafos de ênfases e os parágrafos de outros assuntos, disciplinados, especialmente, pela NBC TA 706. A inserção dos referidos parágrafos acontece logo após o parágrafo de opinião do auditor, e seu conteúdo expõe informação que, no julgamento do auditor, é relevante para chamar a atenção do leitor do relatório, na tentativa de aumentar o poder informativo deste.

O parágrafo de ênfase trata de assunto que está apresentado no conjunto das demonstrações financeiras, mas que o auditor considera vital para o entendimento das demonstrações, conforme explica Longo (2011). Entretanto, esta inserção pode aumentar a percepção de risco do usuário, uma vez que uma mesma informação está contida, por exemplo, nas notas explicativas às demonstrações contábeis auditadas e, novamente, é mencionada, pelo auditor, em seu relatório, como aquela referente à incertezas de continuidade. Contudo, tal menção também pode derivar de atitude conservadora do auditor, na intenção de melhorar o conteúdo informacional do seu relatório.

No parágrafo de outros assuntos, de acordo com a NBC TA 706, não estão inclusos assuntos divulgados nas demonstrações financeiras, mas aqueles relacionados com trabalho do auditor. Apesar da menção a esses assuntos no relatório ser bastante comum, só a partir de 2010, com a referida norma, este parágrafo passou a ganhar uma secção exclusiva.

Nesta perspectiva, o presente estudo procura atingir dois objetivos, que são: identificar os fatos abordados nos parágrafos de ênfase e nos parágrafos de outros assuntos dos relatórios de auditoria emitidos para as companhias abertas pertencentes aos níveis diferenciados de governança corporativa da BM\&FBOVESPA e analisar o tratamento destes, quanto às orientações estabelecidas nas NBC TA's que regulam o assunto.

O período temporal delimitado para o estudo se refere aos exercícios sociais de 2010 e 2011, que representam os anos iniciais de aplicação dos normativos relacionados à auditoria independente, o que torna oportuna a realização dessa pesquisa, cujas constatações podem colaborar para identificação da adaptação brasileira às normas internacionais de auditoria e a necessidade ou não de ajustes destas ao contexto nacional. Nisto reside a sua importância.

Este estudo está apresentado da seguinte forma: uma seção introdutória, na qual é contextualizado o tema e definido os objetivos da pesquisa; três seções destinadas a discutir o conteúdo e estrutura do relatório do auditor independente estabelecido nas normas de auditoria vigentes, sua capacidade informativa como informação contábil e a diferenciação entre os parágrafos de ênfase e o de outros 
assuntos; as seções seguintes apresentam os procedimentos metodológicos, a análise dos resultados e as considerações finais.

\section{REFERENCIAL TEÓRICO}

\subsection{Estrutura e Conteúdo do Relatório do Auditor Independente segundo as Normas de Auditoria}

O exercício da auditoria independente é prática regulamentada por autoridades reguladoras e não são raros estudos que analisem o impacto da inserção de novas normas no exercício da profissão. Como exemplo, cita-se o estudo de Silva e Robles Junior (2008) que objetivou analisar os impactos na atividade de auditoria independente com a introdução da Lei Sarbanes-Oxley. Os resultados encontrados confirmam que os auditores perceberam os impactos oriundos da introdução da Sox no seu dia-a-dia. Para os pesquisados, segundo os autroes, a Sox aumentou a fiscalização sobre a profissão; agregou maior credibilidade às demonstrações financeiras, ao trabalho de auditores e contadores e contribuiu para o aumento dos honorários de auditoria.

Em relação à aderência normativa do conteúdo informacional do parecer de auditoria, cita-se a pesquisa de Assing, Ávila e Alberton (2010) que objetivou investigar a obediência às normas na reavaliação de ativos imobilizados e nos pareceres emitidos pela auditoria independente nas empresas listadas na Bovespa. Dentre os vários objetivos específicos, aquele que se referiu ao parecer, consistiu em averiguar nos pareceres dos auditores independentes se existe $(\mathrm{m})$ ressalva(s) no que concerne ao evento da reavaliação de ativos quando no procedimento existir alguma não conformidade. Os autores constataram que nenhuma empresa com deficiência na periodicidade ou nas notas explicativas apresenta ressalva no parecer, nem mesmo alguma ênfase.

Assim, Assing, Ávila e Alberton (2010) observaram que 6 empresas cumpriram as normas no que concerne às exigências mínimas das notas explicativas. No entanto, dessas 6 empresas, 5 delas descumpriram a norma de reavaliar no mínimo de 4 em 4 anos; logo, apenas 1 empresa cumpriu todas as normas estudadas, com isso, apenas o parecer desta empresa poderia ser limpo.

Outro estudo sobre aderência normativa do parecer foi o desenvolvido por Cunha, Beuren e Pereira (2009) que objetivou verificar se os pareceres de auditoria das demonstrações contábeis de empresas de Santa Catarina registradas na Comissão de Valores Mobiliários são apresentados de acordo com as Normas Brasileiras de Contabilidade, nos aspectos formal e informacional. Quanto aos aspectos formais, os autores identificaram a utilização de diversas locuções e expressões não contempladas no modelo do parecer proposto pelo Conselho Federal de Contabilidade, permitindo concluir que tais pareceres podem melhorar em relação aos aspectos formais, conforme estabelecido nas Normas Brasileiras de 
Contabilidade. No que se refere ao aspecto informacional, os autores julgaram como satisfatório, uma vez que os pareceres foram apresentados revestindo-se de compreensibilidade.

Nesta linha de reflexão, a presente pesquisa foi concebida uma vez que o conteúdo do relatório dos auditores independente passa a contemplar nova estrutura, graças à alteração normativa imposta ao mesmo. Tal alteração visa adequação das Normas Brasileiras de Contabilidade aos padrões internacionais, motivo pelo qual o Conselho Federal de Contabilidade (CFC) aprovou, em 27 de novembro de 2009, através da Resolução CFC no 1231/09, dentre outras, a NBC TA 700 - “Formação da Opinião e Emissão do Relatório do Auditor Independente sobre as Demonstrações Contábeis". Esta norma foi elaborada de acordo com a sua equivalente internacional ISA 700, e passou a vigorar a partir de $1^{\underline{0}}$ de janeiro de 2010.

Anterior a essa mudança, as normas de auditoria vigentes no Brasil eram representadas pela Norma Brasileira de Contabilidade Técnica 11 (NBC T 11), na qual se observa algumas diferenças em relação às NBC TAs, em específico a 700, no que se refere a estrutura do relatório de auditoria. Como exemplo, Longo (2011) cita a mudança na nomenclatura no documento final da auditoria independente que do denominado "parecer do auditor independente" passou a ser chamado de "relatório do auditor independente".

Conforme esclarece Damascena (2011), pode-se citar os tipos de relatório de auditoria como outra mudança:

[...] este documento expressando a opinião do auditor, antes classificado em quatro tipos, agora é alocado em dois grupos, podendo ser não modificada (anteriormente conhecida como parecer sem ressalva) ou modificada (compreendendo o parecer com ressalva, parecer adverso e parecer com abstenção de opinião).

O primeiro tipo de relatório de auditoria, o não modificado, é tratado na NBC TA 700. Citado por Longo (2011) como "relatório limpo", esse parecer é aquele sem nenhum tipo de modificação na opinião do auditor. Para isso, as demonstrações contábeis precisam atender a requisitos, como por exemplo, terem sidas elaboradas de acordo com a estrutura de relatório financeiro aplicável sem apresentar distorções relevantes, causadas por fraude ou erro, entre outros.

A NBC TA 705 - "Modificações na Opinião do Auditor Independente", trata do relatório com opinião modificada que pode ser com ressalva, adversa ou abstenção de opinião.

A opinião com ressalva deve ser aplicada quando:

(a) ele [o auditor], tendo obtido evidência de auditoria apropriada e suficiente, conclui que as distorções, individualmente ou em conjunto, são relevantes, mas não generalizadas nas demonstrações contábeis; ou (b) ele não consegue obter evidência apropriada e suficiente de auditoria para 
suportar sua opinião, mas ele conclui que os possíveis efeitos de distorções não detectadas, se houver, sobre as demonstrações contábeis poderiam ser relevantes, mas não generalizados (NBC TA 705).

A opinião adversa, é utilizada quando o auditor conclui que as distorções, individualmente ou em conjunto, são relevantes e generalizadas para as demonstrações contábeis. Ainda, a NBC TA 705 traz outro tipo de opinião modificada - a abstenção de opinião, e orienta que o auditor deve abster-se de expressar uma opinião quando não se consegue obter evidência de auditoria apropriada e suficiente para suportar opinião, e se houver efeitos de distorções não detectadas nas demonstrações contábeis poderiam ter efeitos relevantes e generalizados.

Com a nova norma em vigor, a estrutura do relatório de auditoria também passou por modificações. O modelo do documento normatizado pela NBC T 11 era composto basicamente por três parágrafos contendo: identificação da entidade e demonstrações contábeis auditadas, extensão dos exames e opinião do auditor. Já a NBC TA 700 exige um modelo mais detalhado, com cinco parágrafos e os demais itens da NBC T 11, como se pode observar no quadro 1, referente ao modelo de relatório com opinião não modificada.

Quadro 1: Estrutura do parecer/relatório de auditoria independente, segundo normatizações do CFC.

\begin{tabular}{|l|l|}
\hline \multicolumn{1}{|c|}{ Estrutura do parecer do auditor } & \multicolumn{1}{c|}{ Estrutura do relatório de auditoria de acordo com a NBC TA } \\
\hline Título; & \multicolumn{1}{c|}{$\mathbf{7 0 0}$} \\
Destinatário; & Título; \\
Parágrafo introdutório; & Destinatário; \\
Parágrafo de extensão; & Parágrafo introdutório; \\
Parágrafo de opinião do auditor; & Responsabilidade da administração sobre as demonstrações \\
Data do parecer do auditor independente; & contábeis; \\
Assinatura do auditor; & Responsabilidade do auditor; \\
Nome da empresa de auditoria. & Opinaão do auditor; \\
& Outras responsabilidades do relatório de auditoria; \\
& Assinatura do auditor; \\
& Data do relatório do auditor independente; \\
& Endereço do auditor independente. \\
\hline
\end{tabular}

Fonte: elaboração própria, baseada na NBC T 11 e na NBC TA.

Com uma nova estrutura mais detalhada, devido à padronização com as normas internacionais de auditoria, o relatório passa a ter maior conteúdo informacional, principalmente para os investidores que são os principais interessados no relatório de auditoria.

Comparando com a norma anterior, observam-se algumas novas exigências, dentre as quais, cita-se a inserção, no parágrafo introdutório, das notas explicativas.

Outro incremento informacional ao novo modelo de relatório se visualiza, principalmente, quanto à diferenciação da responsabilidade da administração e do auditor, quando se refere às demonstrações contábeis auditadas. Enquanto no 
modelo antigo essa diferença era resumida no primeiro parágrafo do parecer, na modelagem vigente se estende por três parágrafos, para detalhar, em aderência ao estabelecido na NBC TA 700, a responsabilidade do auditor, no contexto da auditoria das demonstrações contábeis, e quanto à administração, ficou mais claro o fato de além da elaboração e apresentação adequada das demonstrações contábeis, competelhe a determinação de controles internos necessários para tanto.

Após a seção de responsabilidades vem o parágrafo de opinião, no qual o auditor expressa sua opinião sobre as demonstrações contábeis e referencia à estrutura de relatório financeiro aplicável, utilizada para elaborar as demonstrações contábeis (item 43 da NBC TA 700).

Na última parte do relatório, conforme a NBC TA 700, encontram-se a assinatura do auditor independente, a data e a localidade em que a o relatório foi emitido.

\subsection{Capacidade Informativa do Relatório dos Auditores Independentes}

A auditoria externa surgiu da necessidade de gerar informação para os usuários - os stakeholders - de caráter patrimonial, financeira e de geração de lucro, através das demonstrações contábeis, com maior credibilidade, como afirma Almeida, M. (2010, p.2), "como medida de segurança contra a possibilidade de manipulação de informações, os futuros investidores passaram a exigir que as demonstrações fossem examinadas por um profissional independente da empresa e de reconhecida capacidade técnica".

É mediante o relatório que o auditor expressa sua opinião a respeito das demonstrações contábeis, como destaca Araújo (2006), através do parecer que o auditor assegura as informações que estão à disposição dos usuários, trazendo mais fidedignidade às demonstrações auditadas.

E ainda é salientado como objetivos gerais do auditor, segundo a NBC TA 200, item 11 (a) e (b):

(a) obter segurança razoável de que as demonstrações contábeis como um todo estão livres de distorção relevante, independentemente se causadas por fraude ou erro, possibilitando assim que o auditor expresse sua opinião sobre se as demonstrações contábeis foram elaboradas, em todos os aspectos relevantes, em conformidade com a estrutura de relatório financeiro aplicável; e

(b) apresentar relatório sobre as demonstrações contábeis e comunicar-se como exigido pelas NBC TAs, em conformidade com as constatações do auditor.

Neste contexto ainda Almeida, K. e Vasconscelo (2007) destacam que além de um relátorio anual de obrigação das companhias abertas, o parecer dos auditores é um instrumento formalizador de comunicação entre o auditor e o usuários.

No entanto, para que o relátorio seja otimizado, Sá (2002, p.196), adverte: “A integridade exige que o profissional não se esconda atrás de palavras de sentido 
duplo, de frases evasivas, de abusos de tecnicismo ou de neologismos que possam ofuscar a clareza de um parecer ou opinião", fatores que podem comprometer o grau de informação transmitida aos usuários como também a eficiência do relatório dos Auditores.

Ainda nesta perspectiva, Oliveira e Bispo (2009) evidenciam a importância do auditor neste tipo de informação, “[...] frente à relevância das informações financeiras, o auditor é decisivo para certificar a qualidade dos dados registrados e sua consequente divulgação aos usuários dos relatórios".

Por outro lado, Jacques e Macagnan (2011) lembram que as empresas também têm direcionado esforços na divulgação das suas informações, através dos relatórios anuais para incentivar a captação de novos investidores, garantindo a continuidade das empresas e o desenvolvimento econômico. A qualidade e a transparência destas informações contribuem para redução da assimetria de informações entre os agentes e auxilia na tomada de decisão dos investidores.

Conforme explica Healy e Palepu (2001) (apud Jacques; Macagnan 2011), “[...] a assimetria informacional ocorre quando, em um modelo de informação financeira ou econômica, algum agente possui informação sobre certa empresa ou ativo superior a outro agente". Colocando assim os agentes em desequilíbrio no acesso à informações, ocasionando vantagens ao que tivesse maior informação e em detrimento a isto desvantagens ao que tivesse menor informação.

A base da decisão dos usuários é tomada sob as informações transmitidas e auditas, surgindo aí a importância do auditor mediante os usuários, como mostra Niyama et al.(2011) quando explica que ao assegurar as informações fornecidas pela empresa, o auditor está dando credibilidade a esta informação e reduzindo a assimetria existente na relação do controlador, protegendo assim o investidor.

Algo que vem a contribuir com a redução da assimetria informacional no Brasil é o processo de convergência das normas de auditorias com intuito de uma padronização o que pode gerar maior uniformidade. Ao adotar uma linguagem contábil padrão e sobre os mesmos princípios contábeis fornece a informação maior comparabilidade e contribui para os usuários de diferentes países a analise e tomada de decisão (MAIA; FORMIGONI 2011).

Conforme discutido na seção anterior, o relatório dos auditores independentes passou por mudanças que segundo Longo (2011, p. 322):

[...] ajuda a promover o entendimento pelos usuários e propicia credibilidade no mercado global. Esse melhor entendimento e credibilidade facilitam a atuação das entidades no mercado global, seja na obtenção de crédito, no relacionamento com fornecedores e clientes, barateando de forma geral, os custos das entidades.

Apesar das mudanças referentes ao conteúdo informacional do relatório, ao qual foi aumentando o número de parágrafo, como anteriormente discutido, o parágrafo de ênfase, objeto da presente pesquisa, continuou a ser previsto. 
Estabelecido por norma própria, a NBC TA 706, o parágrafo de ênfase possui a função de chamar a atenção dos usuários para informações consideradas relevantes para adequada interpretação das demonstrações contábeis e não contempladas nos demais parágrafos do relatório. Independente do tipo de relatório expresso pelo auditor - relatório sem ressalva, com ressalva, opinião adversa ou com abstenção de opinião - o parágrafo de ênfase pode ser utilizado para trazer informação relevante aos usuários, lembrando-se, ainda, que o assunto enfatizado pela ênfase não configura e nem modifica a opinião do auditor.

Para os propósitos deste estudo, torna-se necessário discorrer mais aprofundadamente sobre ênfases nos relatórios de auditoria externa, cujos comentários estão na seção seguinte.

\subsection{Informações adicionais no Relatório dos Auditores Independentes: parágrafo de ênfase e parágrafo de outros assuntos}

A Resolução CFC n 1.233, de 27 de dezembro de 2009, aprovou a NBC TA 706 que trata do parágrafo de Ênfase e do parágrafo de Outros Assuntos, no novo formato do relatório dos auditores independentes.

A ênfase se enquadra na secção Outras Responsabilidades do Relatório, apesar desse título ser pouco usual no Brasil, de acordo com a NBC TA 700 item A34, sua inserção dependerá do julgamento e análise do auditor para o seu devido uso.

Em certas jurisdições fora do Brasil, o auditor pode ter responsabilidades adicionais de emitir relatório de auditoria sobre outros assuntos que são complementares à responsabilidade do auditor segundo as normas de auditoria de emitir relatório de auditoria sobre as demonstrações contábeis. Por exemplo, o auditor pode ser solicitado a relatar determinados assuntos que chamaram sua atenção no decurso da auditoria das demonstrações contábeis. Alternativamente, o auditor pode ser solicitado a emitir relatório de auditoria sobre procedimentos adicionais especificados ou expressar uma opinião sobre assuntos específicos, como a adequação de livros e registros contábeis. As normas de auditoria na jurisdição específica frequentemente fornecem orientação sobre a responsabilidade do auditor com relação a responsabilidades relativas à emissão de relatório de auditoria adicionais específicas na referida jurisdição. Tais responsabilidades adicionais não existem no Brasil (NBC TA 700 item A34).

A ênfase se revela como comunicação adicional do auditor com os usuários do seu relatório que, de acordo com o item 1 (a) e item 4 (a) da NBC TA 706, é a inclusão de um parágrafo referente a assunto que está apropriadamente apresentado no corpo das demonstrações financeiras ou adequadamente divulgado nas notas explicativas, mas o auditor o considera vital para a compreensão das demonstrações e decide chamar atenção do usuário para esse assunto, logo após a secção contendo sua opinião. 
De acordo com o item 7 da NBC TA 706, o parágrafo de ênfase deve ser incluído no relatório imediatamente após o parágrafo de opinião e fazer uso do título "Ênfase" ou outro título apropriado, como também indicar que o assunto abordado não modifica a opinião do auditor.

Ainda como exigências normativas, a ênfase deve ter sempre a menção da nota explicativa a que se refere e fazer referência clara ao assunto, de tal forma que não se utilize de assuntos que não tenham sido abordados pelo conjunto completo das demonstrações contábeis, sugerindo assim que as informações não foram devidamente apresentadas, como adverte Longo (2011, p.348):

O parágrafo de Ênfase deve se limitar a chamar a atenção do usuário para aquilo que está divulgado nas demonstrações financeiras com o cuidado dele não apresentar mais informações do que a própria nota explicativa da administração, pois isso sugere que essas notas não apresentam as divulgações necessárias, o que na prática requereria uma ressalva e não ênfase.

Como visto, poderia ocasionar numa distorção porque o que a priori seria fato para uma ressalva, se transforma numa ênfase e a norma enfatiza que o parágrafo de ênfase não deve substituir uma opinião com ressalva, adversa ou abstenção de opinião (NBC-TA-706 item A3 (a)).

Os assuntos apresentados no parágrafo de ênfase são geralmente relacionados com incertezas (litígio, contingência, problemas de continuidade), aplicação antecipada de nova norma contábil introduzida pelo CFC com efeito disseminado nas demonstrações contábeis de forma generalizada, antes da sua data da vigência, grande catástrofe que tenha efeito, ou que ainda continue fazendo efeito sobre a posição patrimonial e financeira da entidade, mudança na legislação que afetem a entidade, transações relevantes com partes relacionadas. (LONGO, p.348; NBC TA 706 item A1)

O quadro 2 mostra as normas de auditoria que contém casos que exigem a inclusão do parágrafo de ênfase:

Quadro 2 - NBC TA's que exigem inclusão do parágrafo de ênfase

\begin{tabular}{|l|l|}
\hline \multicolumn{1}{|c|}{ Normas } & \multicolumn{1}{|c|}{ Casos que devem ser utilizados o Parágrafo de Ênfase } \\
\hline NBC TA 210 - item 19 & Chamar a atenção dos usuários para divulgação adicional \\
\hline NBC TA 560 - item 12(b) e 16 & $\begin{array}{l}\text { Eventos Subsequentes - Existência de mudanças nas } \\
\text { demonstrações contábeis }\end{array}$ \\
\hline NBC TA 570- item 19 & Existência de incerteza de continuidade \\
\hline NBC TA 800 - item 14 & $\begin{array}{l}\text { Alertar os usuários que as demonstrações foram elaboradas de } \\
\text { acordo com uma estrutura de relatório financeiro para } \\
\text { propósitos especiais }\end{array}$ \\
\hline
\end{tabular}

Fonte: Elaboração própria, baseado no apêndice 1 da NBC TA 706. 
Anteriormente, a NBC T 11.3.7.1 definia parágrafo de ênfase como aquele incluído no relatório dos auditores quando ocorresse incerteza sobre algum fato relevante, cujo desfecho poderia afetar significantemente a posição patrimonial e financeira da empresa; Já as novas normas de auditoria versam sobre algumas exigências para inclusão de parágrafo de ênfase fora da sua norma própria, como mostrado no Quadro 2.

Alguns estudos contêm discussões sobre a eficácia do parágrafo de Ênfase, como exemplo, o trabalho de Damascena et al. (2011) ao observou que fatos relacionados com continuidade da empresa tem se mostrado continuamente repetido, ano após ano, sugerindo a ideia de possíveis problemas que deveriam ser corrigidos, mas que não o foram, podendo revelar a presença de resquícios de descontinuidade, por vários anos, o que justificaria emissão de relatórios com ressalva, abstenção de opinião ou opinião adversa e não assunto de ênfase. Além do que, ao se utilizar de forma generalizada do parágrafo de ênfase, o auditor diminui a eficácia da sua comunicação (NBC TA 706 A6).

Já as informações adicionais relacionadas com o trabalho do Auditor, comumente mencionadas na época de vigência do antigo modelo de parecer, passam a ganhar uma seção especifica, como consequência das modificações no formato do relatório do Auditor Independente. Disciplinado também pela norma NBC TA 706, o denominado parágrafo de outros assuntos deve ser incluído logo após a seção de opinião - ou ênfase, se for o caso. Longo (2011, p.348) diferencia a função desse parágrafo como sendo:

Diferentemente do parágrafo de ênfase, o assunto abordado nesse parágrafo de outros assuntos não está divulgado nas demonstrações financeiras, pois está relacionado com o trabalho (do auditor) e não com as demonstrações financeiras (da entidade).

A norma ainda trata das circunstâncias em que pode ser necessário o uso do parágrafo de outros assuntos (NBC TA 706 item 8, A5 a A9): sendo para casos nos quais se tornam relevantes para o entendimento pelos usuários sobre a auditoria, caso relevante para o entendimento pelos usuários da responsabilidade do auditor ou do seu relatório, emissão de relatório de mais de um conjunto de demonstrações contábeis, restrição a distribuição (ou uso) do relatório de auditoria.

O quadro 3 mostra as normas de auditoria que contém casos que exigem a inclusão do parágrafo de outros assuntos.

Quadro 3 - NBC TA's que exigem inclusão do parágrafo de outros assuntos

\begin{tabular}{|c|l|}
\hline \multicolumn{1}{|c|}{ Normas } & \multicolumn{1}{c|}{$\begin{array}{c}\text { Casos que devem ser utilizados o Parágrafo de Outros } \\
\text { Assuntos }\end{array}$} \\
\hline NBC TA 560 - item 12(b) e 16 & $\begin{array}{l}\text { Eventos Subsequentes - Existência de mudanças nas } \\
\text { demonstrações contábeis }\end{array}$ \\
\hline NBC TA 710 & $\begin{array}{l}\text { Informações Comparativas - Valores Correspondentes e } \\
\text { Demonstrações Contábeis Comparativas, itens 13, 14, 16, 17 e 19; }\end{array}$ \\
\hline
\end{tabular}


NBC TA720

Responsabilidade do Auditor em Relação a Outras Informações Incluídas em Documentos que Contenham Demonstrações

Contábeis Auditadas, item 10(a).

Fonte: Elaboração própria, baseado no apêndice 2 da NBC TA 706

Comparando o quadro 3 com o 2 (anterior), observa-se que o assunto referente a eventos subsequentes que provocam mudanças nas demonstrações contábeis que foram auditadas (reapresentação das demonstrações contábeis) tratado pela NBC TA 560, tanto está listado no apêndice 1 como no 2 da NBC TA 706 que contêm, respectivamente, exigências para parágrafos de ênfase e para parágrafos de outros assuntos.

No entanto, a leitura da NBC TA 560, especialmente no item 16, permite observar menção exclusiva no parágrafo de ênfase, não prevendo, portanto, o tratamento como parágrafo de outros assuntos. Entendemos existir ambiguidade de tratamento normativo deste item, necessitando, portanto, maiores orientações normativas a respeito.

\section{PROCEDIMENTOS METODOLÓGICOS}

Para realização deste estudo, fez-se uso da tipologia de delineamentos proposta por Beuren (2006) que classifica a pesquisa em três categorias: quanto aos objetivos, quanto aos procedimentos e quanto à abordagem do problema.

O estudo realizado se classifica como descritivo quanto ao objetivo, logo que busca descrever os fatores que originaram relatórios com parágrafo de ênfase e parágrafos de outros assuntos. De acordo com Marion et. al. (2002) a pesquisa descritiva não busca manipular informação, mas tem como objetivo a descrição de características de determinado fenômeno ou população.

Foram analisados livros, artigos científicos, revistas e normas especificas que tratavam sobre o assunto abordado, constituindo-se, portanto, na pesquisa bibliográfica. Também se fez uso de Internet (sítio da Bovespa) no qual se teve acesso aos relatórios dos auditores independentes, itens utilizados para coleta dos dados necessários ao atingimento dos objetivos desta pesquisa, valendo-se de pesquisa documental. Assim, quanto aos procedimentos, a pesquisa se classifica como bibliográfica e documental.

Já no aspecto da abordagem do problema, a presente pesquisa se enquadra predominantemente como qualitativa, pois segundo Beuren $(2006$, p.92) "Na pesquisa qualitativa concebem-se análises mais profundas em relação ao fenômeno que está sendo estudado. A abordagem qualitativa visa destacar características não observadas por meio de um estudo quantitativo".

Quanto ao universo da pesquisa, optou-se por estudar as sociedades anônimas que iniciaram a negociação de suas ações e estão inseridas nos níveis diferenciados de governança corporativa da BM\&FBOVESPA, nos últimos 4 anos, totalizando 32 empresas. 
A opção pelas empresas com negociação recente no mercado de capitais se deu pela expectativa de maior adesão das mesmas à sua respectiva estrutura de relatório financeiro aplicável, o que poderia repercutir em menor quantidade de ênfase dos seus auditores.

Deste universo, $87,5 \%$ pertencem ao novo mercado e $25 \%$ participam do segmento "Consumo Cíclico". Os demais segmentos representados no universo pesquisado foram: Financeiros e Outros, com 21,9\% do total; Consumo não cíclico, perfazem 15,7\%; Petróleo, gás e biocombustível e Construção e Transporte representam cada, um percentual de cerca de 12,5\%; e, por fim, Bens Industriais, Utilidade Pública, Telecomunicações e Materiais básico, correspondem a cerca de $3,1 \%$ cada.

Vale salientar ainda que das 32 empresas, 01 foi excluída da amostra por ter ocorrido seu o cancelamento voluntario em janeiro de 2011, se desligando da Bovespa. Assim, obteve-se como amostra final 31 empresas.

Assim, foram coletados os relatórios dos auditores independentes relativos aos exercícios sociais de 2010 e 2011, para cada uma das empresas componentes da população. Entretanto, apenas 25 empresas apresentaram relatório de auditoria independente com parágrafos de ênfases, o que corresponde a 80,64\% do universo. Já os relatórios com parágrafos de outros assuntos totalizam 30, que representa $96,77 \%$ da população estudada no ano de 2010. No ano de 2011 foram 26 relatórios com parágrafos de ênfase representando cerca $83,87 \%$ e o parágrafo de outros assuntos foi utilizado por $100 \%$ das empresas analisadas.

Os dados obtidos foram analisados com apoio da estatística descritiva, procurando caracterizar o que é típico sobre este grupo de empresas, como Crespo aponta (2002) através da coleta, organização dos dados e as descrições dos fatos, se enquadrando assim na estatística descritiva, uma vez procurou-se identificar os conteúdos mais frequentes nos parágrafos em análise.

\section{APRESENTAÇÃO E DISCUSSÃO DOS RESULTADOS}

Primeiramente, procurou-se identificar o perfil das empresas componentes do estudo e algumas características dos relatórios analisados, iniciando-se pelo segmento no qual estão inseridas. Para tanto, elaborou-se a Tabela 1 que mostra a distribuição das empresas listadas na BM\&FBOVESPA de acordo com o segmento.

Tabela 1 - Segmento das empresas listadas na BM\&FBOVESPA

\begin{tabular}{lcc}
\hline \multicolumn{1}{c}{ Segmento de listagem } & Frequência & (\%) \\
\hline Novo Mercado & 27 & 87,1 \\
Nível 2 & 3 & 9,7 \\
Bovespa Mais & 1 & 3,2 \\
Total de relatórios & $\mathbf{3 1}$ & $\mathbf{1 0 0 , 0}$ \\
\hline
\end{tabular}


Fonte: Dados da pesquisa.

Observa-se que é majoritária a participação das empresas no Novo Mercado, com $87,1 \%$, sugerindo ser este segmento mais comum para as empresas que decidiram abrir seu capital, nos últimos 4 anos. Considera-se tratar de um padrão de governança corporativo mais elevado, no qual só pode haver emissão de ações com direito de voto, dentre outras características.

A tabela 2 expõe o período de tempo compreendido entre o encerramento do exercício social de 2010 e 2011 da empresa auditada e a data de emissão do relatório do auditor independente. Salienta-se que em todas as empresas analisadas o exercício social foi encerrado em 31 de dezembro de cada ano.

Tabela 2 - Período de publicação dos relatórios de auditoria independente referente ao exercício de 2010 e 2011

\begin{tabular}{|c|c|c|c|c|}
\hline \multirow{2}{*}{ Período de publicação } & \multicolumn{2}{|c|}{2010} & \multicolumn{2}{|c|}{2011} \\
\hline & Freq. & $(\%)$ & Freq. & $(\%)$ \\
\hline $\begin{array}{l}1^{0} \text { mês subsequente ao exercício } \\
\text { social }\end{array}$ & 1 & 3,2 & 0 & 0,0 \\
\hline $\begin{array}{l}2^{\circ} \text { mês subsequente ao exercício } \\
\text { social }\end{array}$ & 10 & 32,3 & 11 & 35,5 \\
\hline $\begin{array}{l}3^{\circ} \text { mês subsequente ao exercício } \\
\text { social }\end{array}$ & 16 & 51,6 & 19 & 61,3 \\
\hline $\begin{array}{l}4^{\circ} \text { mês subsequente ao exercício } \\
\text { social }\end{array}$ & 3 & 9,7 & 1 & 3,2 \\
\hline $\begin{array}{l}7^{0} \text { mês subsequente ao exercício } \\
\text { social }\end{array}$ & 1 & 3,2 & 0 & 0,0 \\
\hline Total de relatórios & 31 & 100,0 & 31 & 100,0 \\
\hline
\end{tabular}

Fonte: Dados da pesquisa.

Na tabela 2, observa-se que mais da metade das empresas apresentaram o seu relatório no mês de março de 2011, 3ํำ mês subsequente ao encerramento do exercício social de 2010, sendo $87,10 \%$ desses documentos emitidos nos três primeiros meses posteriores ao final do exercício social de 2010. Da mesma forma, os relatórios de 2011 foram datados, predominantemente, dentro do primeiro trimestre de 2012, melhorando o percentual para 96,77\%. A importância dessa lacuna de tempo conduz a reflexão sobre a tempestividade do relatório do auditor, como informação contábil.

A tabela 3 apresenta a quantidade de empresas de auditoria que emitiram os relatórios estudados. Observa-se que $96,8 \%$ desse relatórios foram emitidos pelas Big Four (Deloitte Touche Tohmatsu, Ernst \& Young Terco, KPMG e Pricewaterhousecoopers)

Tabela 3 - Quantidade de empresas de auditoria que emitiram os relatórios estudados

\begin{tabular}{lccccc}
\hline \multicolumn{1}{c}{ Empresas de auditoria } & Freq. & $\mathbf{2 0 1 0}$ & $\mathbf{( \% )}$ & Freq. & $\mathbf{2 0 1 1}$ \\
\hline Deloitte Touche Tohmatsu & 10 & 32,3 & 10 & 32,3 \\
Ernst \& Young Terco & 9 & 29,0 & 9 & 29,0
\end{tabular}




$\begin{array}{lcccc}\text { KPMG } & 6 & 19,4 & 6 & 19,4 \\ \text { Pricewaterhousecoopers } & 5 & 16,1 & 5 & 16,1 \\ \text { BDO Auditores Independentes } & 1 & 3,2 & 1 & 3,2 \\ \text { Total de relatórios } & \mathbf{3 1} & \mathbf{1 0 0 , 0} & \mathbf{3 1} & \mathbf{1 0 0 , 0}\end{array}$

Fonte: Dados da pesquisa.

Dentre as empresas de auditoria, destaca-se a Deloitte, por concentrar o maior número de auditagens representando quase 1/3 dos relatórios analisados. Foi possível verificar também que, apesar do predomínio das Big Four, encontra-se a BDO, mesmo com modesta participação.

Este resultado corrobora com o verificado em Oliveira et al. (2010) quando realizou a análise de 50 pareceres de auditoria de companhias, no qual $80 \%$ deles foram emitidos pela quatros maiores empresas de auditoria do mundo.

Todos os 31 relatórios analisados, de ambos os exercícios sociais, são do tipo sem ressalvas, ou seja, não possuem modificação na opinião do auditor.

Em relação à extensão dos relatórios analisados, tem-se a tabela 4 que informa a quantidade de parágrafos por cada relatório de auditoria.

Tabela 4 - Quantidade de parágrafos nos relatórios de auditoria independente

\begin{tabular}{lccccc}
\hline Quantidade de Parágrafos & Freq. & $\mathbf{2 0 1 0}$ & $\mathbf{( \% )}$ & Freq. & $\mathbf{2 0 1 1}$ \\
\hline 4 parágrafos & 1 & 3,2 & 0 & 0,0 \\
5 parágrafos & 3 & 9,7 & 2 & 6,5 \\
6 parágrafos & 4 & 12,9 & 3 & 9,7 \\
7 parágrafos & 13 & 41,9 & 21 & 67,7 \\
8 parágrafos & 8 & 25,8 & 5 & 16,1 \\
9 parágrafos & 2 & 6,5 & 0 & 0,0 \\
Total de relatórios & $\mathbf{3 1}$ & $\mathbf{1 0 0 , 0}$ & $\mathbf{3 1}$ & $\mathbf{1 0 0 , 0}$ \\
\hline
\end{tabular}

Fonte: Dados da pesquisa.

Considerando o universo de relatórios que apresentaram número superior ao estabelecido na NBC TA 700 para aqueles relatórios sem ressalvas, ou seja, 06 ou mais parágrafos por relatório, anos de 2010 e 2011, tem-se 87,1\% e 93,5\% respectivamente deles contemplando informações adicionais, além dos parágrafos padrões exigidos. Este dado estimula a identificação e análise dos assuntos abordados pelos auditores nos parágrafos adicionais, denominados de parágrafos de ênfase e de parágrafos de outros assuntos.

Dando continuidade a tabela 5 expõe os assuntos abordados nos parágrafos de ênfases e possibilita constatar que, em 2010, 78,1\% dos relatórios analisados abordam ênfase referente a critérios contábeis divergentes, segundo o qual as práticas de elaboração das demonstrações contábeis adotadas no Brasil, para o exercício social anterior (2009), diferem das práticas adotadas pelo IFRS, em observância ao disposto, 
por exemplo, nos itens 12(b) e 16 da NBC TA 56. Essa divergência foi causada, segundo os relatórios analisados, pela diferença de avaliação nos investimentos societários, entre as normas adotadas no Brasil e as internacionais.

Tabela 5 - Motivos da criação dos parágrafos de ênfase

\begin{tabular}{lcccc}
\hline \multicolumn{1}{c}{ Assuntos Abordados } & \multicolumn{2}{c}{$\mathbf{2 0 1 0}$} & $\mathbf{2 0 1 1}$ & $\mathbf{( \% )}$ \\
\hline Critérios contábeis divergentes & 25 & 78,1 & 26 & 86,7 \\
$\begin{array}{l}\text { Reapresentação das demonstrações } \\
\text { contábeis }\end{array}$ & 2 & 6,3 & 0 & 0,0 \\
Incertezas de continuidade & 2 & 6,3 & 0 & 0,0 \\
Assuntos diversos & 3 & 9,4 & 4 & 13,3 \\
Total geral de parágrafos de ênfase & $\mathbf{3 2}$ & $\mathbf{1 0 0 , 0}$ & $\mathbf{3 0}$ & $\mathbf{1 0 0 , 0}$ \\
\hline
\end{tabular}

Fonte: Dados da pesquisa.

Para 2011, a menção em parágrafo de ênfase sobre divergências de critérios contábeis é acentuada, elevando o percentual de relatórios com essa informação para $86,7 \%$.

Tal predominância de ênfase, relativa ao assunto devidamente tratados nas notas explicativas, instiga reflexão sobre a eficácia da mesma, ao reforçar o questionamento proposto por Almeida e Vasconcelos (2007) segundo o qual até que ponto o parágrafo de ênfase traz informação adicional ao leitor do parecer/relatório?

Conforme discutido em seções anteriores, os assuntos abordados em parágrafos de ênfases dos relatórios de auditoria podem também estarem contidos em notas explicativas integrantes das demonstrações contábeis auditadas. Nesta perspectiva, a tabela 6 retrata a quantidade de assuntos apresentados no parágrafo de ênfase que já haviam sido tratados em nota explicativa às demonstrações contábeis auditadas.

Tabela 6 - Parágrafos de ênfases abordando o mesmo assunto em notas explicativas

\begin{tabular}{lcccc}
\hline \multicolumn{1}{c}{ Parágrafos de ênfase } & \multicolumn{2}{c}{$\mathbf{2 0 1 0}$} & \multicolumn{2}{c}{$\mathbf{2 0 1 1}$} \\
\hline $\begin{array}{l}\text { Assuntos abordados em notas } \\
\text { explicativas }\end{array}$ & 29 & 90,6 & 30 & 100,0 \\
$\begin{array}{l}\text { Assuntos não abordados em notas } \\
\text { explicativas }\end{array}$ & 3 & 9,4 & 0 & 0,0 \\
Total geral de parágrafos de ênfase & $\mathbf{3 2}$ & $\mathbf{1 0 0 , 0}$ & $\mathbf{3 0}$ & $\mathbf{1 0 0 , 0}$ \\
\hline
\end{tabular}

Fonte: Dados da pesquisa.

Pela leitura da tabela 6, observa-se que mais de 90\% em 2010 e $100 \%$ em 2011 dos parágrafos de ênfase tratam de assuntos já apresentados em notas explicativas, podendo sugerir alto grau de aderência aos itens 1 (a) e 4 (a) da NBC TA 706, segundo os quais a ênfase trata de assunto que está apropriadamente apresentado no corpo das demonstrações financeiras ou adequadamente divulgado nas notas 
explicativas. Por outro lado, reflete-se sobre a redundância da informação e se questiona: o parágrafo de ênfase no relatório de auditoria transmite novas informações ao leitor?

Tabela 7 - Quantidade de assuntos abordados por cada relatório estudado

\begin{tabular}{lcccc}
\hline \multicolumn{1}{r}{ Assuntos Abordados } & \multicolumn{2}{c}{$\mathbf{2 0 1 0}$} & \multicolumn{2}{c}{$\mathbf{2 0 1 1}$} \\
& Freq. & $\mathbf{( \% )}$ & Freq. & (\%) \\
\hline Nenhum assunto & 6 & 19,4 & 5 & 16,1 \\
Um assunto & 20 & 64,5 & 22 & 71,0 \\
Dois assuntos & 3 & 9,7 & 4 & 12,9 \\
Três assuntos & 2 & 6,5 & 0 & 0,0 \\
Total de relatórios & $\mathbf{3 1}$ & $\mathbf{1 0 0 , 0}$ & $\mathbf{3 1}$ & $\mathbf{1 0 0 , 0}$ \\
\hline
\end{tabular}

Fonte: Dados da pesquisa.

Outro aspecto a observar diz respeito ao fato de que a inserção de parágrafos de ênfases nos relatórios de auditoria independente não encontra limitações, cabendo ao auditor o julgamento do quanto abordar. Assim, as tabelas 7 e 8 evidenciam a quantidade e os assuntos descritos em cada relatório analisado. 64,5\% dos relatórios de 2010 abordaram exclusivamente o assunto de critérios contábeis divergentes, tal comentário só não está presente em 19,4\% deles. Da mesma forma, 71\% dos relatórios de 2011 abordou um único assunto, também relacionado à ênfase sobre critérios contábeis divergentes. O assunto "critérios contábeis divergentes" está contido em todos os relatórios de auditoria independente que inseriram parágrafos de ênfase.

Além dos parágrafos de ênfases, a NBC TA 706 prevê a utilização de parágrafos de outros assuntos, cuja diferenciação reside no tipo de assunto abordado que não deve está divulgado pelo conjunto de demonstrações financeiras, pois se relaciona, conforme visto, com assunto relevante para os usuários entenderem a auditoria, a responsabilidade do auditor ou o relatório de auditoria, ou seja, relacionada com o trabalho do auditor.

Tabela 8 - Quantidade de assuntos abordados por cada relatório estudado

\begin{tabular}{l|c|c}
\hline \multicolumn{1}{c|}{ Assuntos abordados nos parágrafos de ênfase } & \multicolumn{2}{c}{ Quantidade } \\
\cline { 2 - 3 } & $\mathbf{2 0 1 0}$ & $\mathbf{2 0 1 1}$ \\
\hline Critérios contábeis divergentes & 20 & 22 \\
\hline $\begin{array}{l}\text { Critérios contábeis divergentes e Reapresentação das demonstrações } \\
\text { contábeis }\end{array}$ & 1 & 0 \\
\hline Critérios contábeis divergentes e Incertezas de continuidade & 1 & 0 \\
\hline Critérios contábeis divergentes e Assuntos diversos & 1 & 4 \\
\hline $\begin{array}{l}\text { Critérios contábeis divergentes, Reapresentação das demonstrações } \\
\text { contábeis e Assuntos diversos }\end{array}$ & 1 & 0 \\
\hline
\end{tabular}




\begin{tabular}{l|l|l}
\hline $\begin{array}{l}\text { Critérios contábeis divergentes, Incertezas de continuidade e Assuntos } \\
\text { diversos }\end{array}$ & 1 & 0 \\
\hline
\end{tabular}

Fonte: Dados da pesquisa.

A tabela 9 mostra que os 31 relatórios analisados, apresentaram 37 parágrafos de outros assuntos em 2010 e 35 em 2011, número superior aos respectivos parágrafos de ênfases do ano de 2010 e 2011, que foram 32 e 30 respectivamente.

Na tabela 8, observa-se que, em 2010,81,1\% e, em 2011, 88,6\% dos parágrafos de outros assuntos se reportam a divulgação de informação suplementar, a demonstração do valor adicionado, que, pelas normas internacionais não é obrigatória, sendo que em 2010 62,2\% e em 2011 80\% dos parágrafos de outros assuntos abordaram apenas esse assunto.

No entanto, o item 19 da NBC TA 210, recomenda, nesta circunstância, chamar atenção do leitor através de parágrafo de ênfase. Apesar disto, nos relatórios analisados a comunicação é feita para chamar a atenção do leitor sobre a extensão do exame de auditoria que alcançou também a informação suplementar, caracterizando, portanto, o parágrafo de outros assuntos.

Por fim, no ano de 2010, 5,4\% dos parágrafos de outros assuntos abordaram a reapresentação das demonstrações contábeis (tabela 8). Este fato, conforme tabela 5, foi tratado como ênfase em 6,3\% das ênfases analisadas. Já no ano de 2011, até a data da coleta de dados, não houve reapresentação das demonstrações contábeis.

Esta falta de uniformidade nos relatórios de auditoria analisados, quanto ao tratamento do assunto "reapresentação das demonstrações contábeis", pode derivar da ambiguidade presente nas NBC TA's que tratam do tema. Conforme já discutido, os apêndices 1 e 2 da NBC TA 706, consideram ênfase ou parágrafo de outros assuntos aquele relacionado com a NBC TA 560 - Eventos Subsequentes, itens 12(b) e 16. Porém, o item 16 da NBC TA 560, considera textualmente como ênfase.

Tabela 9 - Parágrafos de outros assuntos

\begin{tabular}{lcccc}
\multicolumn{1}{c}{ Assuntos abordados } & \multicolumn{2}{c}{$\mathbf{2 0 1 0}$} & \multicolumn{2}{c}{$\mathbf{2 0 1 1}$} \\
& Freq. & $\mathbf{( \% )}$ & Freq. & (\%) \\
\hline $\begin{array}{l}\text { Informação Suplementar - Demonstração do } \\
\text { valor adicionado }\end{array}$ & 30 & 81,1 & 31 & 88,6 \\
$\begin{array}{l}\text { Auditoria dos valores correspondentes do } \\
\text { exercício anterior }\end{array}$ & 5 & 13,5 & 3 & 8,6 \\
$\begin{array}{l}\text { Reapresentação das demonstrações } \\
\text { contábeis }\end{array}$ & 2 & 5,4 & 0 & 0,0 \\
$\begin{array}{l}\text { Operações com partes relacionadas } \\
\begin{array}{l}\text { Total geral de parágrafos de outros } \\
\text { assuntos }\end{array}\end{array}$ & 0 & 0,0 & 1 & 2,9 \\
\hline Fonte: Dados da pesquisa. & 37 & $\mathbf{1 0 0 , 0}$ & 35 & $\mathbf{1 0 0 , 0}$ \\
\hline
\end{tabular}

Fonte: Dados da pesquisa.

Do exposto, observa-se que não há uniformidade nos relatórios de auditoria independente analisados, quanto ao tratamento do assunto "reapresentação das 
demonstrações contábeis", uma vez que em alguns relatórios foi apresentado como ênfase, e em outros como parágrafo de outros assuntos, demonstrando existência de conflitos nas NBC TA's que tentam padronizar esse tratamento, bem como na escolha do auditor sobre em qual seção/parágrafo devem ser abordados.

\section{CONSIDERAÇÕES FINAIS}

Os objetivos que nortearam este estudo foram: identificar os fatos abordados nos parágrafos de ênfase e nos parágrafos de outros assuntos dos relatórios de auditoria emitidos para as companhias abertas pertencentes aos níveis diferenciados de governança corporativa da BM\&FBOVESPA e analisar o tratamento destes, quanto às orientações estabelecidas nas NBC TA's que regulam o assunto.

Quanto ao primeiro objetivo, os resultados encontrados permitiram identificar o assunto "critérios contábeis divergentes" inserido em todos os relatórios analisados que fizeram uso do parágrafo de ênfase, tanto em 2010, como em 2011. Além deste, a "reapresentação das demonstrações contábeis" e "incertezas de continuidade" também foram citados como ênfases nos relatórios de 2010.

Ainda em relação ao objetivo de identificar os fatos abordados nos relatórios dos auditores estudados, em particular em seus parágrafos de outros assuntos, detectou-se a menção sobre "informação suplementar", "auditoria dos valores correspondentes do exercício anterior" e "operações com partes relacionadas", nos dois anos e "reapresentação das demonstrações contábeis", adicionalmente em 2010.

No que se refere ao segundo objetivo do estudo, analisar o tratamento dos parágrafos de ênfase e nos de outros assuntos, nos relatórios estudados, confrontadas com as orientações estabelecidas nas NBC TA's 706, 560 e 210, observou-se a existência de tratamento ambíguo do assunto "reapresentação das demonstrações contábeis" que foram considerados nas referidas normas e nos relatórios analisados ora como ênfase, ora como parágrafo de outros assuntos.

Do exposto, concluiu-se que o assunto "reapresentação das demonstrações contábeis" é tratado pelas NBC TA's e nos relatórios dos auditores independentes analisados, de forma ambígua, quando se relaciona a seção / parágrafo destinado a sua menção. Tal conclusão pode sinalizar a necessidade de maiores orientações normativas a respeito.

Uma limitação do estudo que pode ser visualizada é a reduzida quantidade de relatórios dos auditores independentes analisados, comparado ao universo de relatórios emitidos para as sociedades anônimas que passam pelo processo de auditoria independente nos seus demonstrativos contábeis.

Para futuros estudos, sugere-se atualizar o banco de dados com relatórios de auditoria das mesmas empresas estudadas, para os exercícios sociais findos em 2012 e 2013, como forma de verificar a permanência ou não do tratamento ambíguo do assunto "reapresentação das demonstrações contábeis". Outra sugestão se refere à ampliação do número de empresas cujos relatórios de auditoria foram analisados. 
Ainda como sugestão, recomenda-se realizar estudo que investigue a percepção dos auditores independentes sobre os impactos das NBC TA's no conteúdo informativo do seu relatório.

\section{REFERÊNCIAS}

ALMEIDA, K. K. N. de; VASCONCELOS, M. T. C.. Conteúdo Informativo do Parecer dos Auditores Independentes sobre Demonstrações Contábeis de Empresas Brasileiras. In: I Congresso da ANPCONT - Associação Nacional de PósGraduação em Ciências Contábeis, 2007, Gramado. Anais do I Congresso da ANPCONT, 2007.

ALMEIDA, M. C. Auditoria: um curso moderno e completo. $7^{\circ}$ ed. São Paulo: Atlas, 2010.

ARAUJO, F. J. Compreensão do parecer do auditor independente no Brasil. Revista Brasileira de Contabilidade, v. 139, p. 71-82, jan./fev. 2003.

ASSING, Il.; AVILA, R. V. de; ALBERTON, L. Atendimento às Normas na Reavaliação de Ativos Imobilizados e nos Pareceres Emitidos por Auditoria Independente. Revista de Informação Contábil, Recife, vol. 4, n.ํ 1, p. 01-20, JanMar/2010

BEUREN, Ilse Maria (Org.). Como elaborar trabalhos monográficos em Contabilidade: teoria e prática. São Paulo: Atlas, 2004

BOVESPA. Disponível em: <http://www.bovespa.com.br>. Acesso em: 27.fev.2012

CRESPO, A. A. Estatística Fácil. $17^{\circ}$ ed., São Paulo: Saraiva,2002

CONSELHO FEDERAL DE CONTABILIDADE. Normas Técnicas de Auditoria Brasília: CFC, 2009.

DAMASCENA, L. G. Pareceres de auditoria: um estudo das ressalvas e parágrafos de ênfase constantes nas demonstrações contábeis das companhias abertas brasileiras. 2011. Dissertação (Mestrado em Ciências Contábeis) - Programa Multiinstitucional e Inter-Regional de Pós-Graduação em Ciências Contábeis, da Universidade de Brasília (UnB), da Universidade Federal da Paraíba (UFPB) e da Universidade Federal do Rio Grande do Norte (UFRN), 2011.

; FIRMINO, José Emerson; PAULO, E. Estudo sobre os Pareces de Auditoria Análise dos Parágrafos de Ênfase e Ressalvas Constantes nas 
Demonstrações Contábeis das Companhias Listadas na Bovespa. Contabilidade Vista \& Revista, v. 22, p. 125-154, 2010.

GIL, A. C. Como elaborar projetos de pesquisa. $4^{\circ}$ ed. São Paulo: Atlas, 2006.

JACQUES, F.; MACAGNAN, C. B. A Relação entre a Evidenciação de Informações nos Pareceres de Auditoria e o Valor das Ações de Companhias Abertas Listadas na Bovespa. In: V Congresso ANPCONT, 2011, Vitoria. V Congresso Anpcont. Vitoria - ES : Anpcont, 2011.

LONGO, C. G. Manual de Auditoria e Revisão de Demonstrações Financeiras Normas Brasileiras e Internacional. $2^{\circ}$ ed., São Paulo: Atlas, 2011.

MAIA, H. A.; FORMIGONI H. Empresas de Auditoria e o Compliance com o Nível de Evidenciação Obrigatório Durante o Processo de Convergência as Normas Internacionais de Contabilidade no Brasil. In: V Congresso ANPCONT, 2011, Vitoria. V Congresso Anpcont. Vitoria - ES : Anpcont, 2011.v. V. p. 71.

CUNHA, P. R. da; BEUREN, I. M.; PEREIRA, E. Análise dos pareceres de auditoria das demonstrações contábeis de empresas de Santa Catarina registradas na Comissão de Valores Mobiliários. RIC - Revista de Informação Contábil, Recife, v. 3, n. 4, p. 44-65, out./dez. 2009.

MARION, J. C.; DIAS, R.; TRALDI, M. C. Monografia para os cursos de Administração, Contabilidade e Economia. $1^{\circ}$ ed., São Paulo: Atlas, 2002.

NIYAMA, J. K.; COSTA, F. M.; DANTAS, J. A.; BORGES, E. F. Evolução da Auditoria Independente no Brasil: Análise Crítica, a Partir da Teoria da Regulação. In: V Congresso ANPCONT, 2011, Vitoria. V Congresso Anpcont. Vitoria - ES: Anpcont, 2011.

SÁ, A. L. de. Curso de auditoria. 10ª ed., São Paulo: Atlas, 2002.

SILVA, A. G. da. ROBLES JÚNIOR, A. Os Impactos na Atividade de Auditoria Independente com a Introdução da Lei Sarbanes-Oxley. Revista Contabilidade e Finanças, São Paulo, v. 19, n. 48, p. 112 - 127, set/out. 2008.

OLIVEIRA, G. J. P.; BISPO, O. N. de A. Qualidade da Auditoria e Gerenciamento de Resultados Contábeis em INITIAL PUBLIC OFFERING (IPO). In: XII SEMEAD, 2009, Cidade Universitária: XII SEMEAD - SIMPÓSIO DE ADMINISTRAÇÃO DA FEA/USP. Cidade Universitária - SP: Semead, 2009. 
OLIVEIRA, R. R.; LIMA, A. C. N. de; ALVES, M. R. M.; VIEIRA, S. dos S. Inserção das Big Four como Prestadoras de Serviço de Auditoria em Sociedades de Capital Aberto: um Estudo em Cinquenta Empresas Listadas na Categoria Nível de Mercado da Bovespa. In: SIMPÓSIO DE EXCELÊNCIA EM GESTÃO E TECNOLOGIA, 2010, Resende, RJ. VII Seget. Resende, RJ: Seget, 2010. 